\title{
Flagellin and GroEL mediates in vitro binding of an atypical enteropathogenic Escherichia coli to cellular fibronectin
}

\author{
Claudia T. P. Moraes ${ }^{1 \dagger}$, Juliana M. Polatto ${ }^{1 \dagger}$, Sarita S. Rossato ${ }^{1}$, Mariana Izquierdo ${ }^{2}$, Danielle D. Munhoz ${ }^{1}$, \\ Fernando H. Martins ${ }^{1}$, Daniel C. Pimenta ${ }^{3}$, Mauricio J. Farfan², Waldir P. Elias', Ângela S. Barbosa ${ }^{1}$ \\ and Roxane M. F. Piazza ${ }^{1 *}$
}

\begin{abstract}
Background: Enteropathogenic Escherichia coli (EPEC) is distinguished mainly by the presence of EPEC adherence factor plasmid (pEAF) in typical EPEC (tEPEC) and its absence in atypical EPEC (aEPEC). The initial adherence to the intestinal mucosa is complex and mediated by adhesins other than bundle-forming pilus, which is not produced by aEPEC. Extracellular matrix (ECM) proteins of eukaryotic cells are commonly recognized by bacterial adhesins. Therefore, binding to ECM proteins may facilitate colonization, invasion and/or signaling by intestinal pathogens. Previous studies from our group demonstrated that aEPEC O26:H11 (strain BA2103) showed high binding activity to fibronectin, not shared by its counterpart, aEPEC O26:HNM.

Results: In the present study, using mass spectrometry after fibronectin-associated immunoprecipitation, two proteins, flagellin (50 kDa) and GroEL (52 kDa), were identified and BA2103 binding ability to fibronectin was inhibited in the presence of anti-H11 and anti-GroEL sera, but not by either naïve rabbit or other unrelated sera. It was also observed that the presence of purified flagellin inhibits adhesion of BA2103 to cellular fibronectin in a dose-dependent manner. Additionally, BA2103 GroEL is similar to the same protein of uropathogenic E. coli.
\end{abstract}

Conclusions: Our results suggest that flagellin may play a role in the in vitro interaction of BA2103 with cellular fibronectin, and GroEL can be an accessory protein in this process.

Keywords: Atypical EPEC, Binding, Fibronectin, Flagellin, GroEL

\section{Background}

Adherence to intestinal cells is a critical step in enteropathogenic Escherichia coli (EPEC) pathogenesis. EPEC expresses intimin adhesin, an adherence factor chromosomally encoded by the eae gene [1], which is involved in the receptors recognition, located at the surface of target cells (translocated intimin receptor - Tir, $\beta 1$ integrin and nucleolin) [2, 3]. The intimin-Tir interaction plays a role in attaching and effacement lesion followed by intestinal colonization. Moreover, EPEC is distinguished by the presence of EPEC adherence factor plasmid (pEAF) in typical EPEC (tEPEC) and its absence

\footnotetext{
* Correspondence: roxane@butantan.gov.br

${ }^{\dagger}$ Equal contributors

${ }^{1}$ Laboratório de Bacteriologia, Instituto Butantan, Av. Vital Brazil, 1500 -

05503-900 São Paulo, SP, Brazil

Full list of author information is available at the end of the article
}

in atypical EPEC (aEPEC) [4]. Also, lack of bundle-forming pilus (BFP) production $[5,6]$, presence of hemolysins [7] and autotransporter proteins $[8,9]$ existing in other diarrheagenic E. coli pathotypes characterize aEPEC [10, 11]. In $\mathrm{EEPEC}$, the role of BFP either in initial contact or in bacteria-bacteria interaction is well established $[12,13]$. However, in aEPEC this adhesion has been attributed to EspA and various accessory adhesins described in other pathogenic E. coli strains [14].

The ability to adhere to extracellular matrix (ECM) proteins has been shown to be essential for the virulence of several pathogens [15]. The ECM proteins comprise a diverse group that function as a barrier, support for epithelial cells, and are responsible for development, growth, and maintenance of mammalian tissues [16]. The composition of ECM differs in various organs, but 
fibronectin, collagen types I to $\mathrm{XV}$, and laminin are common constituents [17]. ECM proteins are commonly recognized by bacterial adhesins and have been shown to act as substrates for bacterial adherence to eukaryotic cells $[15,18-22]$. Enteric bacterial pathogens can interact with ECM either during inflammation or in the tight junctions opening [23]. Therefore, binding to ECM proteins may facilitate colonization, invasion, and/or signaling by intestinal pathogens [17]. Fibronectin is an ECM molecule targeted by several pathogens and is formed by dimers covalently linked by a pair of disulfide bonds near their carboxyl termini [24]. Fibronectin is responsible for connecting the collagen scaffold and other ECM components [22], and was the first eukaryotic cell receptor described for bacteria [18].

Recently, some conserved proteins, such as outer membrane protein A (OmpA), flagellin (FliC) and E. coli GroEL have been described as involved in adhesion, colonization, invasion and dissemination or as major antigens in many important pathogens [25-31]. FliC, the subunit of flagellum structure, contains highly conserved $\mathrm{N}$ - and C-termini, while its central region is significantly variable and provides antigenic differences [32]. FliC is involved in motility and pathogenesis [33-36], and also can interact with cell surface polypeptide receptors on monocytes and activate Toll-like receptors 5 (TLR-5) [37]. GroEL is a multitask protein, which function as a prototypical and indispensable molecular chaperone in stress survival. In addition, this protein presents moonlighting activities acting as a cell surface receptor for various pathogens ligands. Between 250-300 E. coli proteins bind to GroEL, 85 of them are obligate client to GroEL [38].

Previous results from our group demonstrated that a subset of atypical EPEC presented ability to bind to immobilized ECM proteins. Among them, the O26:H11 (BA2103) strain consistently presented the highest binding ability to cellular fibronectin [7]. Taking these results in consideration, we investigated in the current study putative candidates of this particular strain that might mediate binding to cellular fibronectin. Our results indicate that flagellin may play a role in the in vitro interaction with this ECM component, and GroEL can be an accessory protein in this process.

\section{Methods}

\section{Bacterial strains}

Atypical EPEC (aEPEC) strains BA2103 (serotype O26:H11) and 2271-1/85 (serotype O26:HNM, where $\mathrm{NM}$ indicates nonmotile) were previously characterized by the eae+/EAF-/bfpA- genetic profile, lack of production of BFP and production of the localized adherencelike (LAL) pattern on HEp-2 cells [5, 6, 39]. Molecular typing of $f l i C$ defined the $\mathrm{H}$ type of $2271-1 / 85$ strain as
H11 [39]. Binding ability to ECM of supernatant proteins from BA2103 was described elsewhere [7]. A nonpathogenic K12 E. coli DH5 $\alpha$ was included as a control strain [40]. Also, twenty O26:H11 aEPEC strains were employed in the fibronectin binding screening [5, 39]. This study does not involve humans, human data or animals, since all strains employed herein belong to the Bacteriology Laboratory bacterial collection of Butantan Institute, São Paulo, SP, Brazil.

\section{Binding of $E$. coli strains to fibronectin}

In order to confirm the binding ability of BA2103 strain to fibronectin and compare it to $2271-1 / 85$ and DH5 $\alpha$ strains, $40 \mu \mathrm{L}$ of bacteria culture growth $\left(1.5 \times 10^{8}\right)$ were incubated in ELISA microplates previously coated with $1 \mu \mathrm{g}$ of cellular fibronectin, or $1 \mu \mathrm{g}$ of bovine serum albumin (BSA) (Sigma Chemical Co.) at $37^{\circ} \mathrm{C}$ for $4 \mathrm{~h}$ [41]. Also, $40 \mu \mathrm{L}$ of serially diluted bacterial suspensions (from $10^{8}$ to $10^{5}$ ) were tested. An additional assay was done preincubating $10^{7}$ bacterial cells with increasing concentrations of cellular fibronectin (from 0.2 to $25.6 \mu \mathrm{g}$ ) followed by incubation in ELISA microplates previously coated with $1 \mu \mathrm{g}$ of cellular fibronectin. Quantification of adhered bacteria was determined by removing the bacteria adhered to fibronectin and BSA with PBS containing $0.05 \%$ Triton X-100. Serial dilutions were plated onto Luria Bertani (LB) agar plates and the number of bacteria was determined by counting colony-forming units (CFU) [20]. CFU values were obtained from triplicates of four independent experiments.

Additionally, the binding ability to cellular fibronectin of 20 strains belonging to the O26:H11 serotype was accessed employing the crystal violet staining measurement as described elsewhere [42]. Experiments were performed in duplicate of two independent experiments and the average values were calculated.

\section{Protein identification}

Supernatant proteins were obtained by growing BA2103 in $50 \mathrm{~mL}$ of TSB at $37^{\circ} \mathrm{C}$ for $18 \mathrm{~h}(150 \mathrm{rpm})$, followed by centrifugation at $10,000 \mathrm{~g}$ for $15 \mathrm{~min}$. This supernatant was filtered through a $0.22 \mu \mathrm{m}$ membrane and protein concentration was determined by a Bradford assay. Protein identification was achieved by matrixassisted laser desorption ionization-time of flight mass spectrometry (MALDI-TOF) analyses. Prior to MALDITOF analyses, $100 \mu \mathrm{g}$ of supernatant proteins from BA2103 were incubated with $25 \mu \mathrm{g} / \mathrm{mL}$ of fibronectin at $25^{\circ} \mathrm{C}$ for $90 \mathrm{~min}$. Fibronectin-associated proteins were obtained by immunoprecipitation analysis using $\mathrm{A} / \mathrm{G}$ agarose columns (Pierce) conjugated with anti-fibronectin antibodies (Sigma). Proteins recovered from the column were visualized by silver-stained SDS-PAGE, and protein bands were excised from SDS gel for MALDI-TOF 
analyses (Mass Spectrometry Core Laboratory, University of Texas Medical Branch).

\section{Sequence alignments of flagellin and GroEL from Escherichia coli $026: \mathrm{H} 11$ strains}

Amino acid sequences of flagellin (gi|260855903) and GroEL (gi|18028158) obtained by MALDI-TOF analyses were compared to other related sequences available in GenBank database. All sequence alignments and analyses were performed with Basic Local Alignment Search Tool (BLAST) program (http://blast.ncbi.nlm.nih.gov/ BlastAlign.cgi), MUSCLE [43] and BioEdit Sequence Alignment Editor vs 7.2.5.0.

The fliC gene of BA2103 was amplified by PCR and sequenced using primers described elsewhere [44] in order to investigate minor nucleotide alterations. Three additional internal primers (sequence $1 \mathrm{fliC}(\mathrm{R})$ : GCC TGACCTGCTGCG; sequence $2 \mathrm{fliC}(\mathrm{R})$ : CACTGACTT ACCATC; sequence $3 \mathrm{fliC}$ (F): CATGTCTCGTGCG) were designed to obtain full-length $\mathrm{fliC}$ sequence.

\section{H11 flagellin purification}

Flagellin produced by BA2103 (O26:H11) was extracted from $50 \mathrm{~mL}$ cultures as described elsewhere with some modifications [45]. Briefly, bacterial cells were collected by centrifugation, suspended in $2 \mathrm{~mL}$ of phosphatebuffered saline (pH 7.4) and sheared for 2 min in bench mixer (Genie 2) at maximal speed. Cells were kept on ice bath for $1 \mathrm{~min}$ and the procedure was repeated three times. The cell suspension was then centrifuged at $10,000 \mathrm{X} \mathrm{g}$ for $10 \mathrm{~min}$ to remove the bacterial cells. Culture supernatants containing the sheared flagellin were precipitated with acetone. The resulting pellet was suspended in PBS and, finally, submitted to heat treatment $\left(65{ }^{\circ} \mathrm{C}\right.$ for $\left.30 \mathrm{~min}\right)$ to depolymerize filaments into flagellin monomers. Protein concentration was determined using BCA assay (Pierce) and purity was checked by SDS-PAGE and immunoblotting using anti-H11 serum. Also an ELISA was employed in order to check anti-H11 reactivity to purified flagellin.

\section{Detection of flagellin and GroEL in E. coli strains by immunofluorescence}

The presence of flagellin and GroEL was evaluated in three bacterial strains (BA2103, 2271-1/85 and E. coli $\mathrm{DH} 5 \alpha)$ by immunofluorescence employing anti-H11 and anti-GroEL sera. E. coli strains were cultivated at $37{ }^{\circ} \mathrm{C}$ in LB broth for $16-18 \mathrm{~h}$, and a smear from the bacterial pellets was fixed with $4 \%$ paraformaldehyde. Slide glasses with fixed bacteria were washed with phosphatebuffered saline (PBS 0.01 M, pH 7.4) and blocked with $10 \%$ goat serum in PBS (PBS-GS) at $25{ }^{\circ} \mathrm{C}$ for $1 \mathrm{~h}$, followed by incubation at $25{ }^{\circ} \mathrm{C}$ for $2 \mathrm{~h}$ with rabbit antiGroEL (1:500) or rabbit anti-H11 (1:200) antibodies diluted in PBS-GS and goat anti-rabbit IgG conjugated with FITC diluted $1: 250$ or $1: 100$, respectively at $25{ }^{\circ} \mathrm{C}$ for $1 \mathrm{~h}$. Between incubations the reactions were washed twice with PBS, and then slide glasses were mounted with glass coverslips. Bacteria were visualized on Axioskop fluorescence microscope (Zeiss, Germany), with a $400 \mathrm{X}$ magnification.

\section{Binding inhibition to fibronectin}

In order to validate the interaction of flagella and GroEL with cellular fibronectin, an in vitro inhibition assay was performed. BA2103 was cultivated in LB broth and $1.5 \times 10^{7}$ of bacteria suspension was preincubated with serial dilutions of rabbit anti-H11 or rabbit anti-GroEL (1:500 to $1: 8,000)$ (Sigma-Aldrich) antibodies at $37{ }^{\circ} \mathrm{C}$ for $2 \mathrm{~h}$, at $50 \mathrm{rpm}$ in a platform shaker. Bacteria were then incubated at $37{ }^{\circ} \mathrm{C}$ for $4 \mathrm{~h}$ in ELISA microplate wells previously coated with $1 \mu \mathrm{g}$ of cellular fibronectin. Serial dilutions $(1: 500$ to $1: 8,000)$ of naïve rabbit serum, rabbit anti-H9, anti-human vitronectin (Sigma-Aldrich), anti-human C1q and anti-human C3 were employed as negative controls of binding inhibition assay. An additional assay was done by incubating increasing concentrations of purified flagellin (7.8 to $500 \mu \mathrm{g}$ ) in ELISA microplate wells previously coated with $1 \mu \mathrm{g}$ of cellular fibronectin, followed by an incubation of bacteria culture growth $\left(1.5 \times 10^{7}\right)$. Quantification of adhered bacteria was achieved by removing them from microplate wells with PBS containing $0.05 \%$ Triton X-100. Serial dilutions were plated onto LB agar plates and CFU was determined as described elsewhere [20]. CFU values were obtained from triplicates of four independent experiments in the presence or absence of antisera or in the presence or absence of purified flagellin.

\section{Statistical analyses}

The colony-forming units (CFU) and absorbance values were analyzed by Graph Prism ${ }^{\circ}$ 5.01, using unpaired Student's $t$-test. The differences were considered statistically significant when $p \leq 0.05$.

\section{Results}

Binding of $E$. coli strains to cellular fibronectin

The binding ability of BA2103 to cellular fibronectin was compared to another aEPEC strain, a nonmotile O26 (2271-1/85) and a nonmotile K12 E. coli strain. The 2271-1/85 strain differs from BA2103 in terms of lack of motility and flagellin production. The binding of BA2103 to fibronectin was much more pronounced and this difference was statistically significant compared to the binding of the other two strains to this particular ECM component (Fig. 1a). BA2103 bound to cellular fibronectin in a dose-dependent manner and this interaction was specific, since no adhesion to BSA was observed in any 

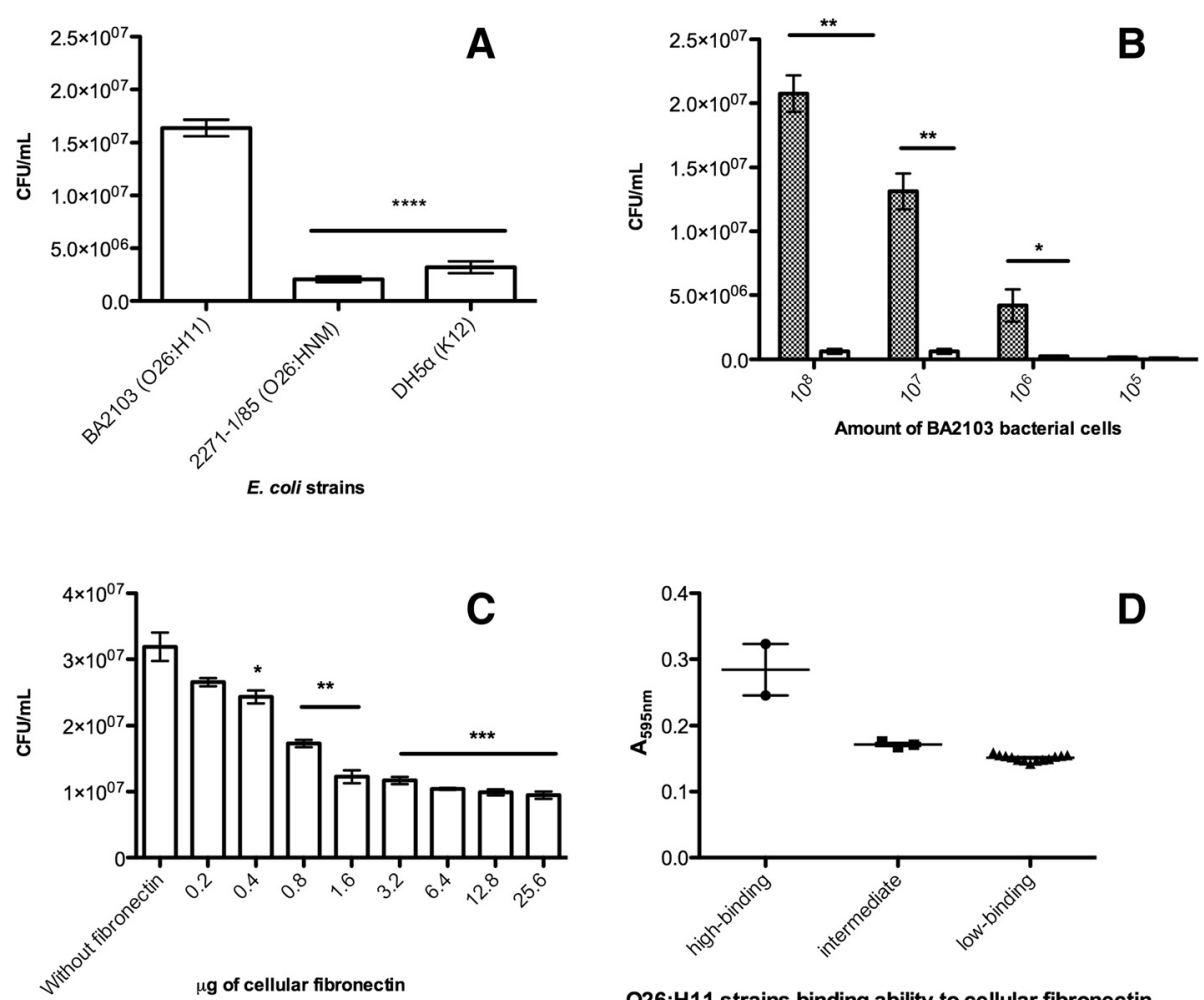

O26:H11 strains binding ability to cellular fibronectin

Fig. 1 Binding assay: a Binding to fibronectin of $40 \mu \mathrm{L}$ of bacteria culture growth of BA2103, 2271-1/85 and DH5a strains incubated in ELISA microplates previously coated with cellular fibronectin, or BSA. b Serial dilutions of BA2103 incubated in ELISA microplates previously coated with cellular fibronectin (hatched bars) or BSA (white bars). c BA2103 preincubated with increasing concentrations of cellular fibronectin prior to incubation in ELISA microplates previously coated with cellular fibronectin. Adhered bacteria were recovered with $0.05 \%$ triton-X100 in PBS and plated on LB agar in serial dilutions and then the colony-forming units were counted. Differences were statistically significant comparing the binding to fibronectin of BA2103 and the other two strains $(p<0.0001)$ and comparing the binding of BA2103 to fibronectin or to BSA independent of bacteria concentration $(p<0.004)$. It was also statistically significant compared the preincubation in absence of fibronectin or in presence of dose-dependent of fibronectin (from $p<0.03$ to 0.0005). $\mathbf{d}$ O26:H11 strains screened by binding ability to cellular fibronectin employing the crystal violet staining measurement. Absorbance's means between high and low binding groups were statistically significant $\left(p<0.0001, R^{2}\right.$ 0.9025) also means difference between high and intermediate were statistically significant $(p=0.0310)$

dilutions of bacterial suspensions (Fig. 1b). Also a competitive dose-dependent and saturable inhibition was observed in preincubation of BA2103 bacterial cells with cellular fibronectin prior to binding to immobilized fibronectin (Fig. 1c).

Furthermore, twenty aEPEC O26:H11 strains were screened by their binding ability to cellular fibronectin by crystal violet staining. Employing this method we were able to arbitrary separate three groups according to their ability to bind to cellular fibronectin: high-binding strains, including BA2103 and BA2459, and low-binding strains, including non-motile 2271-1/85. The statistical analyses showed that the absorbance's means between both groups were statistically significant $\left(p<0.0001, R^{2}\right.$ $0.9025)$ and also the variances between both groups were significant $(p<0.0001)$. The third group presenting intermediate binding ability, comprised by three strains (0791-1/85; 4851-3/86 and IC50) (Fig. 1d).

\section{Identification of proteins involved in the recognition of} cellular fibronectin by BA2103

Employing fibronectin-associated immunoprecipitation, four proteins were identified by mass spectrometry (Fig. 2, Table 1). Two of them, flagellin (gil260855903 - $50 \mathrm{kDa}$ ) and GroEL (gil18028158 - $52 \mathrm{kDa}$ ) with 2.51E-43 and $1.26 \mathrm{E}-22$ of expectation score, respectively, could be considered as putative adhesins for bacterial cell interaction.

In silico analysis were performed in order to investigate which features of BA2103 flagellin or GroEL would confer their binding activities to cellular fibronectin. Multiple alignments of flagellin sequences from O26:H11 strains showed that these proteins are highly conserved, and no sequence unique to aEPEC BA2103 flagellin (FliC $\left.\mathrm{BA2103}_{\mathrm{B}}\right)$ was observed (Additional file 1: Figure S1). Considering that hypervariable domains of flagellin are involved in bacterial adhesion [46], we hypothesize that fibronectin-binding sites could be located on this region 


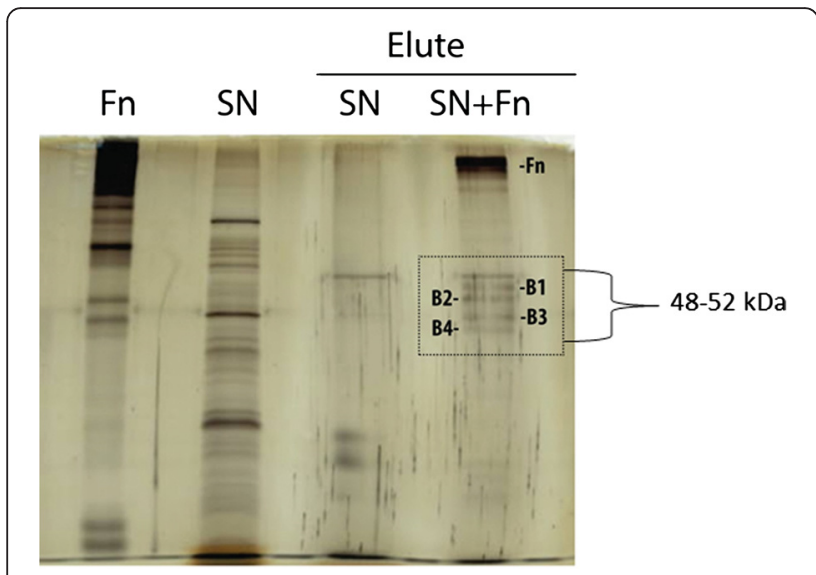

Fig. 2 Co-immunoprecipitation of fibronectin-bound proteins. $100 \mu \mathrm{g}$ of supernatant proteins (SP) were incubated with $25 \mu \mathrm{g} / \mathrm{mL}$ of Fn (Sp + Fn) or PBS (SP + PBS) and the mixture was added to a column with anti-Fn antibodies for co-immunoprecipitation analysis. Immunoprecipitated proteins were visualized by silver stained SDS-PAGE and protein bands (B1, B2, B3 and B4) were excised for MALDI-TOF analyses

of the $\mathrm{FliC}_{\mathrm{BA2103}}$. To test this, we performed an alignment by BLASTp of this region (residues 177 to 394) and fibronectin-binding domain of the Staphylococcus aureus FnBPA, a well-characterized fibronectin-binding protein [47]. We found a 14-amino acid sequence (YDVGGDAYTVNVDS) showing $64 \%$ similarity to two motifs of FnBPA, which could be a putative Fn-binding site within $\mathrm{FliC}_{\mathrm{BA} 2103}$ (Additional file 2: Figure S2).

As demonstrated by MALDI-TOF, GroEL of BA2103 is similar to GroEL of E. coli 196 sequence. The results from GroEL alignment sequence showed 65 amino acids variation at equatorial domain 1 between J96 and 11368 O26:H11 strain (Additional file 3: Figure S3). We presented the alignment comparison with only one of $E$. coli O26:H11 (strain 11368), since previous analysis comparing more than 50 sequences, including different E. coli serotypes of H11, H7 and H6, showed $100 \%$ of identity (data not shown). Although the sizes of compared proteins were different, hydrophobic domain at apical domain (amino acids 191-203) is conserved among all analyzed sequences (Additional file 3: Figure S3). Another important feature is that GroEL of J96 is more similar to the sequence found in Shigella sonnei (90,8 \%) than most of E. coli GroEL (88.3 \%) (Table 2).

We also performed an immunofluorescence assay in order to assess surface localization of the two abovementioned proteins. Employing the rabbit anti-H11 serum, flagellin was detected only in BA2103. As expected anti-H11 did not react with non-motile aEPEC (2271-1/85) and non-motile K12 DH5 $\alpha$ (Fig. 3a, b and c). On the other hand, as GroEL is a highly conserved protein, it was detected in intact and non-permeabilized $E$. coli strains, i.e., BA2103, 2271-1/85 and DH5 $\alpha$ (Fig. 3d, e and $\mathrm{f})$.

\section{The role of flagellin and GroEL in the in vitro interaction of BA2103 to cellular fibronectin}

To further demonstrate the role of both proteins in the interaction of BA2103 to cellular fibronectin, we performed a fibronectin binding inhibition assay using specific antibodies against $\mathrm{H} 11$ and GroEL proteins. Both antisera were able to strongly inhibit the binding of BA2103 to fibronectin in vitro independent of sera dilution. These inhibitions either with rabbit anti-H11 or anti-GroEL sera $(p=0.0008)$ were statistically significant when compared to the binding of BA2103 to fibronectin in sera absence and also when we employed naïve rabbit serum which showed no binding inhibition (Fig. 4a). Also, no binding inhibition was observed when we employed rabbit anti-H9 serum or a set of unrelated sera, such as anti-human vitronectin, anti-human $\mathrm{C} 1 \mathrm{q}$ and anti-human C3 (data not shown).

A competitive inhibition assay between BA2103 and flagellin was done by incubating a fixed concentration of cellular fibronectin with increasing concentrations of purified flagellin (Additional file 4: Figure S4) followed by incubation with BA2103 bacterial cells. These results corroborate that flagellin may mediate in vitro binding of BA2103 to cellular fibronectin; since flagellin was able to block in a dose-dependent manner the subsequent interaction of BA2103 bacterial cells to cellular fibronectin (Fig. 4b).

\section{Discussion}

Bacteria can produce proteins that interact with ECM components. These proteins are qualified as MSCRAMMs

Table 1 Identification of fibronectin-associated proteins by MALDI-TOF analyses $\left({ }^{* *} p\right.$ value $=0,05$ and Protein Significance Score $\left.=71\right)$

\begin{tabular}{|c|c|c|c|c|}
\hline Protein & Accession & Average Mass (kDa) & ${ }^{\mathrm{a}} \mathrm{AAs}$ & E-values \\
\hline flagellin (Escherichia coli O26:H11 str.11368) & gi|260855903 & 50.9 & 484 & $2.51 \mathrm{E}-43$ \\
\hline GroEL (Escherichia coli) & gi|18028158 & 52.0 & 277 & $1.26 \mathrm{E}-22$ \\
\hline lysine-tRNA ligase (Escherichia coli) & gi|486212064 & 57.7 & 337 & $1.26 \mathrm{E}-28$ \\
\hline protein S1 & gi|223404 & 61.1 & 158 & $9.98 \mathrm{E}-11$ \\
\hline
\end{tabular}

${ }^{\mathrm{a}}$ Availability of aminoacids

**Protein score is $-10^{*} \log (P)$, where $\mathrm{P}$ is the probability that the observed match is a random event. Protein scores greater than 62 are significant $(p<0.05)$. Protein scores are derived from ions scores as a non-probabilistic basis for ranking protein hits 
Table 2 GroEL Sequence Identity Matrix values generated after alignment by ClustalW among E. coli 996 O4:K6, Shigella sonnei 3233-85 and E. coli 11368 O26:H11

\begin{tabular}{llll}
\hline Isolate & J96 & $3233-85$ & 11368 \\
\hline J96 & ID & 0.908 & 0.883 \\
$3233-85$ & 0.908 & ID & 0.972 \\
11368 & 0.883 & 0.972 & ID \\
\hline
\end{tabular}

(microbial surface components recognizing adhesive matrix molecules) [22]. Thus, ECM proteins can play a bridging role between bacteria and host cells, contributing to activation of signal transduction pathways and control of later steps of pathogenesis [20]. In addition, bacterial colonization and invasion is related to laminin and fibronectin adherence in epithelial cells [17].

The high adhesiveness ability of the O26:H11 strain to ECM components, mainly fibronectin and laminin [7], prompted us to characterize in vitro binding ability of BA2103 to fibronectin with the aim of characterizing putative bacterial proteins involved in this interaction. Our results confirmed the binding of BA2103 bacterial cells to fibronectin. This kind of interaction has been described for enteroaggregative and enterohemorrhagic E. coli fimbrial adhesins [20,21]. In order to identify which proteins could be involved in this process, fibronectin-associated immunoprecipitation was performed.
Our initial thought was that hemolysins could be partially involved in these interactions, since high levels of binding were observed with bacterial supernatant from the strains harboring ehly, $e h x$ and sheA genes [7]. Therefore, we employed bacterial supernatants for fibronectinimmunoprecipitation in the present study. Surprisingly, no hemolysins were identified; on the other hand, after MALDI-TOF analyses four proteins were identified, three of them (lysine tRNA ligase, GroEL and H11 flagellin) present in $E$. coli. Despite the fact that, one cannot exclude the functions of tRNA ligase as a moonlighting protein as previously showed for glycil-tRNA [48]. It is worth to mention that flagellin is abundant in E. coli and is certainly present both in the bacterial membrane and in the supernatant due to physical rupture during cultivation. The same can be applicable for GroEL, considered a moonlighting protein and present not only in the cytoplasm but also on the bacterial membrane and extracellularly [38]. Thus, we decided to focus on the role of flagellin and GroEL.

It has been described that flagella not only contribute to bacterial motility but are also involved in biofilm formation, binding to host proteins, adherence, invasion, and colonization of host cells [25, 33, 36, 49-51]. Concerning EPEC, the detected binding of $\mathrm{H} 6$ flagella, purified from the prototype tEPEC E2348/69, to ECM components was in a dose-dependent manner to collagen and with less

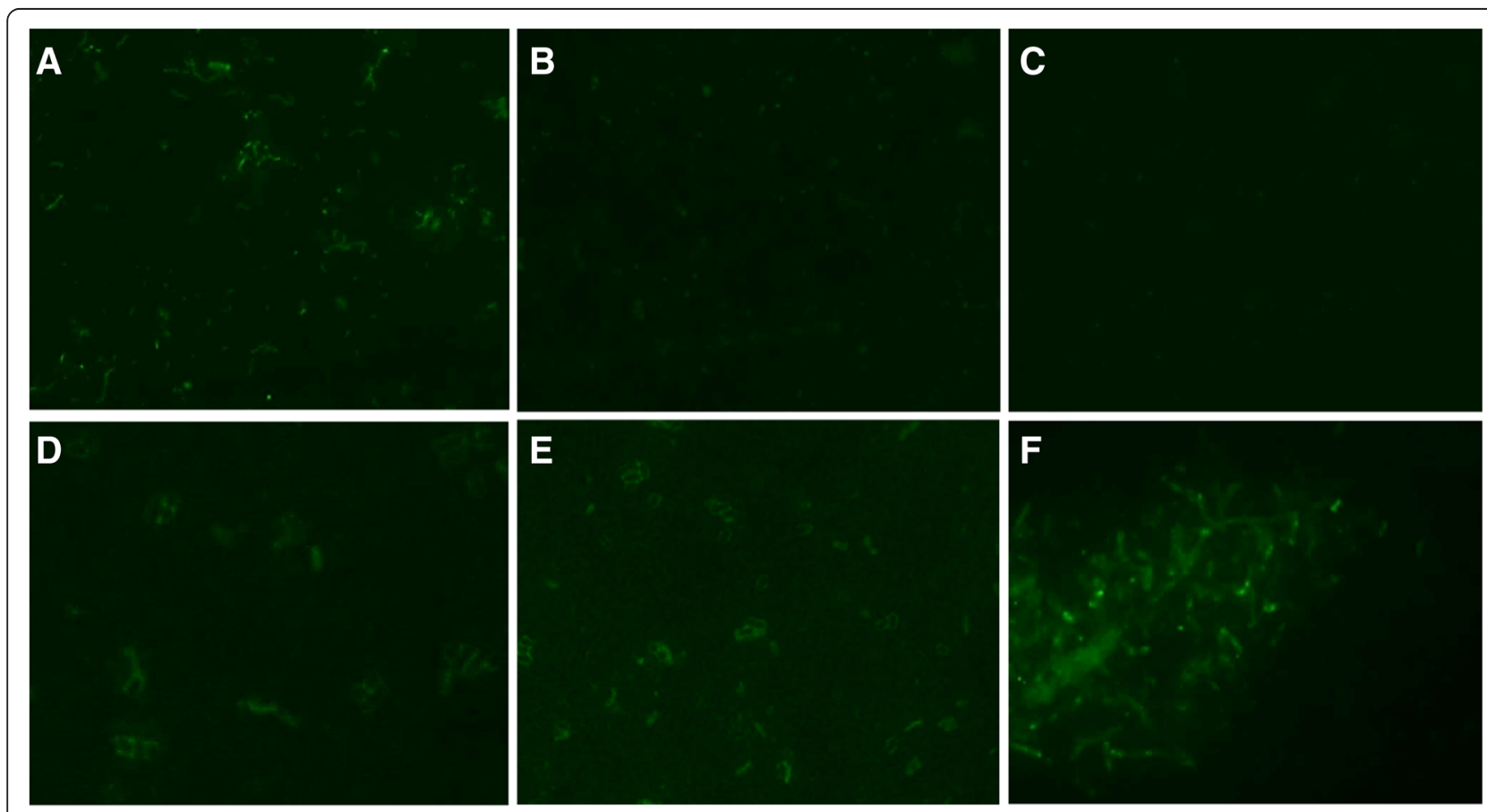

Fig. 3 Immunofluorescence assay. Bacterial pellets from aEPEC BA2103 (panels a and d), aEPEC 2271-1/85 (panels b and e) and K12 DH5a (panels $\mathbf{c}$ and $\mathbf{f}$ ) were fixed with $4 \%$ paraformaldehyde on slide glasses and incubated with rabbit anti-H11 (panels a to c) or with rabbit anti-GroEL (panels $\mathbf{d}$ to $\mathbf{f}$ ) followed by an incubation with goat anti-rabbit lgG conjugated to FITC. The immunoassay with intact, non-permeabilized bacteria was visualized on Axioskop fluorescence microscope with a 400X magnification 


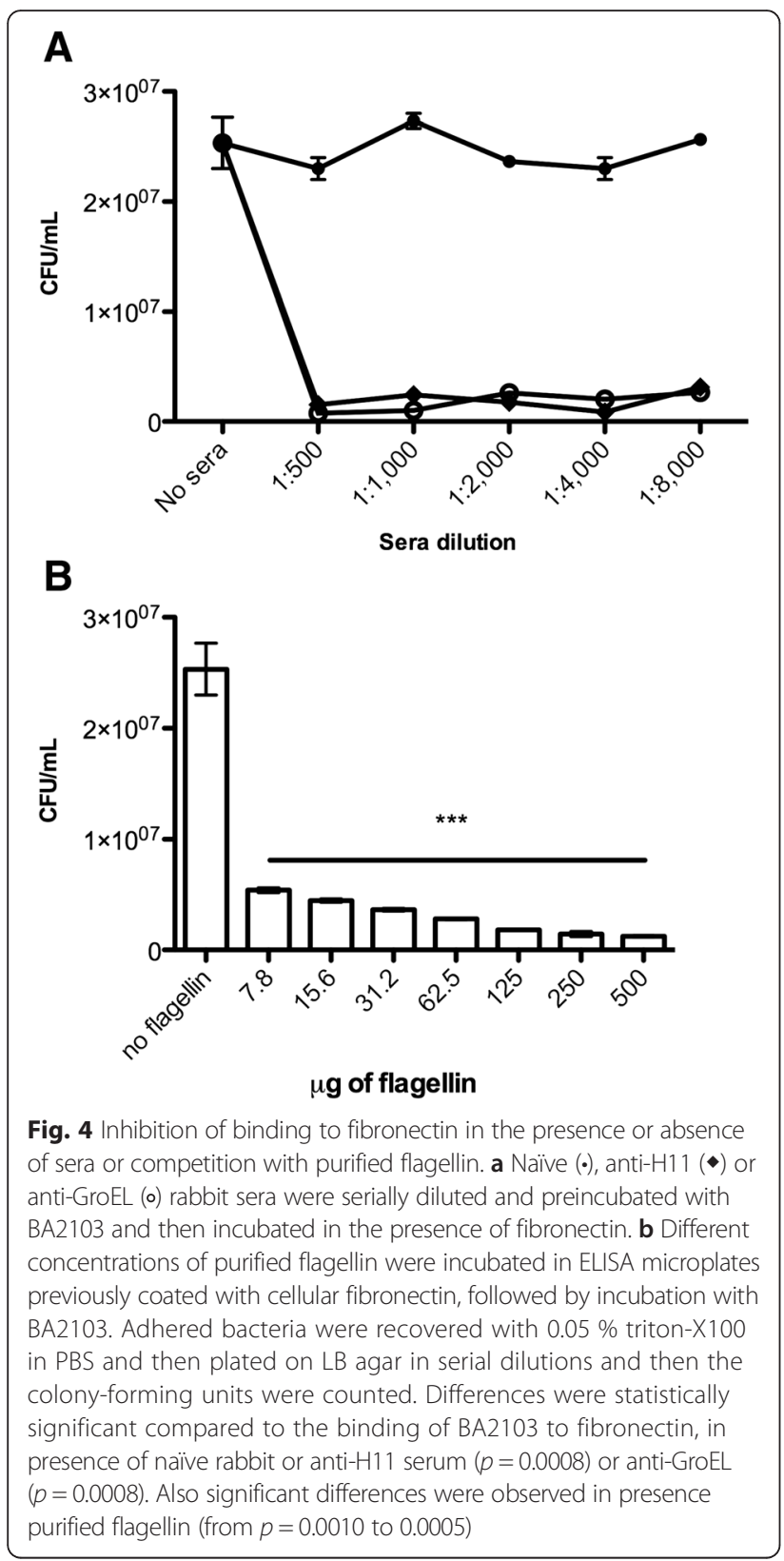

affinity to laminin and fibronectin, but not to vitronectin. Furthermore, the prototype tEPEC E2348/69, but not fliC mutant bound to ECM proteins [35]. Also, FliC in aEPEC serotype O51:H40 plays a role in adhesion, invasion and IL-8 production [36].

In our study, both aEPEC strains belong to the serotype O26:H11 but only the motile BA2103 produce flagellin and interact with fibronectin, leading us to attribute a role for the $\mathrm{H} 11$ flagellin in mediating bacterial binding to fibronectin. Thus, the interaction between flagellin and fibronectin may contribute to aEPEC BA2103 efficiency in tissue colonization, indirectly demonstrated herein by a significant inhibition of the binding of aEPEC binding to fibronectin in presence of different dilutions of rabbit anti-H11 serum, but not to naïve rabbit serum. Furthermore, purified flagellin (H11) was able to block in a dosedependent manner the subsequent interaction of BA2103 bacterial cells to cellular fibronectin.

In an attempt to characterize BA2103 flagellin features that confer its binding to cellular fibronectin, in silico analysis was performed. No fibronectin-binding domain has been described in flagellin so far. Despite that, our data demonstrate a specific interaction between $\mathrm{FliC}_{\mathrm{BA} 2103}$ and fibronectin, suggesting the presence of binding sites for this ECM molecule. As hypervariable domains of flagellin bear adhesive properties [46], we selected this specific region of $\mathrm{FliC}_{\mathrm{BA} 2103}$ to search for Fn-binding sites, identifying a 14-amino acid residue similar to two motifs of $S$. aureus FnBPA involved in interactions with fibronectin [47]. The YDVGGDAYTVNVDS identified sequence could be a putative Fn-binding site, although specific experiments such as peptide array and site-directed mutagenesis need to be performed for mapping the Fnbinding sites within $\mathrm{FliC}_{\mathrm{BA2103}}$.

GroEL was described as a conserved and immunodominant protein in Brucella and avian pathogenic E. coli $[52,53]$. Besides its classical function as a chaperone, a role as adhesin- or invasin-mediating factor has been described for different pathogens such as Mollicutes, Salmonella Typhimurium, Mycobacterium bovis and E. coli [54-56]. Moreover, it has been shown that GroEL homolog of $E$. coli, the $60-\mathrm{kDa}$-heat shock protein, is not only intracellularly located but also associated with cell surface [57]. Our immunofluorescence data indicate that GroEL was also found to be associated with cell surface in all three tested strains. In aEPEC BA2103 anti-GroEL serum significantly reduced its binding capacity to fibronectin, which further supports a function for this protein as one adhesin, since no reduction was observed when unrelated sera were employed. The folding activity of GroEL on substrate proteins is dependent of its ATP induced conformational change [58]. There are three important domains described for this protein: apical, intermediate and equatorial 1 and 2 [30]. The hydrophobic binding is found on apical domain [59] and the flexibility of this site of protein facilities the binding with substrates, GroES (co-chaperonin) and non-natives polypeptides [30]. In our results, the MALD-TOF analysis identified a GroEL of BA2103 O26:H11 similar to GroEL to uropathogenic E. coli J96 [60]. When compared to the majority of the H11 FliC $E$. coli subtype sequences in GenBank, a difference of 65 amino acids was verify between them at Equatorial domain 1. Although no changing has been observed at the conserved binding site, a significant size alteration can affect conformation of GroEL. As the function of GroEL is folding related, conformational changes could improve exposition of binding site and 
higher the binding to fibronectin, consequently. This interaction would facilitate the interaction between this ECM and others E. coli proteins [38]. Nevertheless, structural analyses are necessary to elucidate this mechanism.

The role of flagellin and GroEL in the in vitro interaction of aEPEC BA2103 to cellular fibronectin herein demonstrate cannot be extended to all O26:H11 aEPEC strains. In fact, among the collection of twenty O26:H11 strains tested in this study, only BA2459 presented the same binding ability, as previously described [7]. The nonmotile strains were classified in the low-binding group and it is worth to mention that among these strains, three harbor the ehxA gene (O26 TR EPM; 3451-3/86 and 2012-1) [39].

A frequent attribute among aEPEC strains is the finding of specific phenotypes or putative virulence factors produced by subgroups, sometimes one strain belonging to the same serotype $[9,36,61,62]$. Adhesion, invasion, and IL-8 production in cultured intestinal epithelial cells mediated by flagella [36], induction of mucus production [62], production of hemolysis and binding to ECM molecules [7], as well as toxin production [9] are examples of such characteristic of aEPEC.

\section{Conclusions}

Taken together our results suggest that flagellin may play a role in the in vitro interaction of BA2103 with cellular fibronectin, and GroEL can be an accessory protein, in this process as an additional strategy acquired by this strain. Besides, considering ours and previous data, it is clear that these data cannot be extended to all O26:H11 aEPEC strains. The significance of these proteins in host cell interaction of other aEPEC serotypes is under investigation by our group.

\section{Availability of supporting data}

All the supporting data are included as additional files.

\section{Additional files}

Additional file 1: Figure S1. Multiple sequence alignment of flagellin from Escherichia coli O26:H11 strains. Sequence alignment was performed using MUSCLE server. (DOCX $22 \mathrm{~kb}$ )

Additional file 2: Figure S2. Sequence alignment of the hypervariable region of aEPEC BA2103 flagellin and the fibronectin-binding region of Staphylococcus aureus FnBPA. A. Predicted amino acid sequence of aEPEC BA2103 flagellin ( $\mathrm{FliC}_{\mathrm{BA2103}}$ ), highlighting the hypervariable region (yellow). B. Amino acid sequence of $S$. aureus FnBPA, highlighting the Fn-binding region (grey). C. BLASTp results showing a 14-aa sequence of $\mathrm{FliC}_{\text {BA2103 (residues } 198}$ to 211 - query) with $64 \%$ of similarity to two motifs of FnBPA (residues 764 to 777 and 802 to 815 - subject). D. Multiple sequence alignment of these three regions highlighting the conserved (dark grey) and similar (grey) amino acid residues. (DOCX $167 \mathrm{~kb}$ )

Additional file 3: Figure S3. Amino acids sequences alignment of GroEL. The first sequence corresponding to E. coli J96 O4:K6 (gi|18028158), which was identified by MALDI-TOF of BA2103 isolated after fibronectinassociated immunoprecipitation. The sequence was compare to GroEL of
Shigella sonnei 3233-85 (gil391279593) and E. coli 11368 O26:H11 (gi|260853213:5396024-5397670) using BioEdit Sequence Alignment Editor vs 7.2.5.0 after alignment by ClustalW. The open box shows the amino acids differences among sequences at GroEL equatorial domain 1. The tagged sequence corresponding to conserved hydrophobic binding domain of GroEL. (DOCX 26 kb)

Additional file 4: Figure S4. Flagellin purification and characterization. A. Nitrocellulose membrane containing $10 \mu \mathrm{g}$ of purified flagellin. Immunoblotting reaction was carried out using anti-H11 rabbit serum (1) and naïve rabbit serum (2), followed by goat lgG anti-rabbit peroxidase conjugate. Arrow indicates flagellin. B. Titration of anti-H11 and naïve rabbit sera by indirect ELISA. (TIFF $26 \mathrm{~kb}$ )

\section{Competing interests}

The authors declare that they have no competing interests.

\section{Authors' contributions}

Laboratory investigations and data analysis were performed by CTPM, JMP, SSR, DDM. FHM, CTPM performed the bioinformatics analyses. MJF, Ml performed the proteins identification through immunoprecipitation, analyzed the mass spectrometry and assisted the preparation of the manuscript. RMFP, ASB, designed the study. RMFP, CTPM, ASB, MJF, DCP, WPE assisted in the development of the research proposal and preparation of manuscript. All authors read and approved the final manuscript.

\section{Acknowledgements}

This work was supported by grants 04/12136-5 and 06/05145-0 from São Paulo Research Foundation (FAPESP) and from Conselho Nacional de Desenvolvimento Científico e Tecnológico (CNPq - 470648/2008-2). SSR was recipient of FAPESP fellowship (06/58303-5). Work in the MJF laboratory was supported by grant 1120809 from Fondo Nacional de Desarrollo Científico y Tecnológico (FONDECYT). The rabbit anti-H11 and rabbit anti-H9 sera were kindly provided by Prof. Tânia A.T. Gomes and Prof. Beatriz E. C. Guth (Federal University of São Paulo, Brazil).

\section{Author details}

'Laboratório de Bacteriologia, Instituto Butantan, Av. Vital Brazil, 1500 05503-900 São Paulo, SP, Brazil. ${ }^{2}$ Centro de Estudios Moleculares, Departamento de Pediatría, Hospital Dr. Luis Calvo Mackenna, Universidad de Chile, Santiago, Chile. ${ }^{3}$ Laboratório de Bioquímica e Biofísica, Instituto Butantan, São Paulo, SP, Brazil.

Received: 2 June 2015 Accepted: 3 December 2015 Published online: 18 December 2015

References

1. Jerse AE, Yu J, Tall BD, Kaper JB. A genetic locus of enteropathogenic Escherichia coli necessary for the production of attaching and effacing lesions on tissue culture cells. PNAS (USA). 1990;87(20):7839-43.

2. Sinclair JF, O'Brien AD. Cell surface-localized nucleolin is a eukaryotic receptor for the adhesin intimin-gamma of enterohemorrhagic Escherichia coli O157:H7. J Biol Chem. 2002;277(4):2876-85.

3. Muza-Moons MM, Koutsouris A, Hecht G. Disruption of cell polarity by Enteropathogenic Escherichia coli enables basolateral membrane proteins to migrate apically and to potentiate physiological consequences. Infect Immun. 2003;71(12):7069-78.

4. Kaper JB. Defining EPEC. Rev Microbiol. 1996;27:130-3.

5. Abe CM, Trabulsi LR, Blanco J, Blanco M, Dahbi G, Blanco JE, et al. Virulence features of atypical enteropathogenic Escherichia coli identified by the eae (+) EAF-negative stx (-) genetic profile. Diagn Microbiol Infect Dis. 2009; 64(4):357-65.

6. Nara JM, Cianciarullo AM, Culler HF, Bueris V, Horton DS, Menezes MA, et al. Differentiation of typical and atypical enteropathogenic Escherichia coli using colony immunoblot for detection of bundle-forming pilus expression. J Appl Microbiol. 2010;109(1):35-43.

7. Magalhães CA, Rossato SS, Barbosa AS, Santos TO, Elias WP, Sircili MP, et al. The ability of haemolysins expressed by atypical enteropathogenic Escherichia coli to bind to extracellular matrix components. Mem Instituto Oswaldo Cruz. 2011;106(2):146-52. 
8. Abreu AG, Bueris V, Porangaba TM, Sircili MP, Navarro-Garcia F, Elias WP Autotransporter protein-encoding genes of diarrheagenic Escherichia coli are found in both typical and atypical enteropathogenic E. coli strains. Appl Environ Microbiol. 2013;79(1):411-4.

9. Ruiz RC, Melo KC, Rossato SS, Barbosa CM, Corrêa LM, Elias WP, et al. Atypical enteropathogenic Escherichia coli secretes plasmid encoded toxin. Biomed Res Int. 2014;2014(896235):1-8.

10. Trabulsi LR, Keller R, Gomes TA. Typical and atypical enteropathogenic Escherichia coli. Emerg Infect Dis. 2002;8(5):508-5013.

11. Hernandes RT, Elias WP, Vieira MA, Gomes TA. An overview of atypical enteropathogenic Escherichia coli. FEMS Microbiol Lett. 2009;297(2):137-49.

12. Girón JA, Ho ASY, Schoolnik GK. An inducible bundle-forming pilus of enteropathogenic Escherichia coli. Science. 1991;254(5032):710-3.

13. Cleary J, Lai LC, Shaw RK, Straatman-Iwanowska A, Donnenberg MS, Frankel G, et al. Enteropathogenic Escherichia coli (EPEC) adhesion to intestinal epithelial cells: role of bundle-forming pili (BFP), EspA filaments and intimin. Microbiology. 2004;150(3):527-38.

14. Torres AG, Zhou X, Kaper JB. Adherence of diarrheagenic Escherichia coli strains to epithelial cells. Infect Immun. 2005;73(1):8-29.

15. Westerlund JA, Weisgraber KH. Discrete carboxyl-terminal segments of apolipoprotein E mediate lipoprotein association and protein oligomerization. J Biol Chem. 1993;268(21):15745-50.

16. Berrier AL, Yamada KM. Cell-matrix adhesion. J Cell Physiol. 2007;213(3):565-73.

17. Dorsey CW, Laarakker MC, Humphries AD, Weening EH, Bäumler AJ. Salmonella enterica serotype Typhimurium MisL is an intestinal colonization factor that binds fibronectin. Mol Microbiol. 2005;57(1):196-211.

18. Kuusela P. Fibronectin binds to Staphylococcus aureus. Nature. 1978; 276(5689):718-20.

19. Konke ME, Christensen JE, Keech AM, Monteville MR, Klena JD, Garvis SG. Identification of a fibronectin-binding domain within the Campylobacter jejuni CadF protein. Mol Microbiol. 2005;57(4):1022-35.

20. Farfan MJ, Inman KG, Nataro JP. The major pilin subunit of the AAF/I fimbriae from enteroaggregative Escherichia coli mediates binding to extracellular matrix proteins. Infect Immun. 2008;76(10):4378-84.

21. Farfan MJ, Cantero L, Vidal R, Botkin DJ, Torres AG. Long polar fimbriae of enterohemorrhagic Escherichia coli 0157:H7 bind to extracellular matrix proteins. InfectImmun. 2011;79(9):3744-50.

22. Chagnot C, Listrat A, Astruc T, Desvaux M. Bacterial adhesion to animal tissues: protein determinants for recognition of extracellular matrix components. Cell Microbiol. 2012;14(11):1687-96.

23. Walia B, Castaneda FE, Wang L, Kolachala VL, Bajaj R, Roman J, et al. Polarized fibronectin secretion induced by adenosine regulates bacterial-epithelial interaction in human intestinal epithelial cells. Biochem J. 2004;382(2):589-96.

24. Pankov R, Yamada KM. Fibronectin at a glance. J Cell Sci. 2002;115(20):3861-3.

25. Allen-Vercoe E, Woodward MJ. Colonization of the chicken caecum by afimbriate and aflagellate derivatives of Salmonella enterica serotype Enteritidis. Vet Microbiol. 1999;69(4):65-275.

26. Mendoza JA, Dulin P, Warren T. The lower hydrolysis of ATP by the stress protein GroEL is a major factor responsible for the diminished chaperonin activity at low temperature. Cryobiology. 2000;41(4):319-23.

27. Parker CT, Guard-Petter J. Contribution of flagella and invasion proteins to pathogenesis of Salmonella enterica serovar Enteritidis in chicks. FEMS Microbiol Lett. 2001;204(2):287-91.

28. Ragione RM, Cooley WA, Velge P, Jepson MA, Woodward MJ. Membrane ruffling and invasion of human and avian cell lines is reduced for aflagellate mutants of Salmonella enterica serotype Enteritidis. Int J Med Microbiol. 2003;293(4):261-72.

29. Berndt A, Müller J, Borsi L, Kosmehl H, Methner U. Reorganisation of the caecal extracellular matrix upon Salmonella infection-relation between bacterial invasiveness and expression of virulence genes. Vet Microbiol. 2009;133(1-2):123-37.

30. Chaudhuri TK, Verma VK, Maheshwari A. GroEL assisted folding of large polypeptide substrates in Escherichia coli. Present scenario and assignments for the future. Prog Biophys Mol Biol. 2009;99(1):42-50.

31. Baranova IN, Vishnyakova TG, Bocharov AV, Leelahavanichkul A, Kurlander R, Chen Z, et al. Class B scavenger receptor types I and II and CD36 mediate bacterial recognition and proinflammatory signaling induced by Escherichia coli, lipopolysaccharide, and cytosolic chaperonin 60. J Immunol. 2012; 188(3):1371-80.

32. Reid SD, Selander RK, Whittam T. Sequence diversity of flagellin (fliC) alleles in pathogenic Escherichia coli. J Bacteriol. 1999;181(1):153-60.
33. Girón JA, Torres AG, Freer E, Kaper JB. The flagella of enteropathogenic Escherichia coli mediate adherence to epithelial cells. Mol Microbiol. 2002; 44(2):361-79.

34. Beatson SA, Minamino T, Pallen MJ. Variation in bacterial flagellins: from sequence to structure. Trends Microbiol. 2006;14(4):151-5.

35. Erdem AL, Avelino F, Xicohtencatl-Cortes J, Girón JA. Host protein binding and adhesive properties of $\mathrm{H} 6$ and $\mathrm{H} 7$ flagella of attaching and effacing Escherichia coli. J Bacteriol. 2007;189(20):7426-35.

36. Sampaio SC, Gomes TA, Pichon C, du Merle L, Guadagnini S, Abe CM, et al. The flagella of an atypical enteropathogenic Escherichia coli strain are required for efficient interaction with and stimulation of interleukin-8 production by enterocytes in vitro. Infect Immun. 2009;77(10):4406-13.

37. Hayashi F, Smith KD, Ozinsky A, Hawn TR, Yi EC, Goodlett DR, et al. The innate immune response to bacterial flagellin is mediated by Toll-like receptor 5 . Nature. 2001:410(6832):1099-103.

38. Henderson B, Fares MA, Lund PA. Chaperonin 60: a paradoxical, evolutionarily conserved protein family with multiple moonlighting functions. Biol Rev Cambridge Philos Soc. 2013;88(4):955-87.

39. Piazza RM, Delannoy S, Fach $P$, Saridakis HO, Pedroso MZ, Rocha LB, et al. Molecular and phenotypic characterization of Escherichia coli O26:H8 among diarrheagenic E. coli $\mathrm{O} 26$ strains isolated in Brazil. App Environ Microbiol. 2013;79(22):6847-54

40. Sambrock J, Russel DW. Molecular Cloning. 3rd ed. New York: Cold Spring Harbour Laboratory Press; 2001.

41. Barbosa AS, Abreu PA, Neves FO, Atzingen MV, Watanabe MM, Vieira ML, et al. A newly identified leptospiral adhesin mediates attachment to laminin. Infect Immun. 2006;74(11):6356-64.

42. Zulfakar SS, White JD, Ross T, Tamplin ML. Bacterial attachment to immobilized extracellular matrix proteins in vitro. Int J Food Microbiol. 2012;157(2):210-7.

43. Edgar RC. MUSCLE: a multiple sequence alignment method with reduced time and space complexity. BMC Bioinformatics. 2004;113(5):1-19.

44. Fields PI, Blom K, Hughes HJ, Helsel LO, Feng P, Swaminathan B. Molecular characterization of the gene encoding $\mathrm{H}$ antigen in Escherichia coli and development of a PCR-restriction fragment length polymorphism test for identification of E. coli O157:H7 and O157:NM. J Clin Microbiol. 1997;35(5): 1066-70.

45. Braga C, Massis LM, Alencar BC, Rodrigues MM, Sbrogio-Almeida ME, Ferreira LC. Cytotoxic T cell adjuvant effects of three Salmonella enterica flagellins. Braz J Microbiol. 2008;39(1):44-9.

46. Ramos HC, Rumbo M, Sirard JC. Bacterial flagellins: mediators of pathogenicity and host immune responses in mucosa. Trends Microbiol. 2004;12(11):509-17.

47. Schwarz-Linek U, Pilka ES, Pickford AR, Kim JH, Höök M, Campbell ID, et al. High affinity streptococcal binding to human fibronectin requires specific recognition of sequential F1 modules. J Biol Chem. 2004;279(37):39017-25.

48. Andreev DE, Hirnet J, Terenin IM, Dmitriev SE, Niepmann M, Shatsky IN. Glycyl-tRNA synthetase specifically binds to the poliovirus IRES to activate translation initiation. Nucleic Acids Res. 2012:40(12):5602-14.

49. Arora SK, Ritchings BW, Almira EC, Lory S, Ramphal R. The Pseudomonas aeruginosa flagellar cap protein, FliD, is responsible for mucin adhesion. Infect Immun. 1998;66(3):1000-7.

50. O'Toole GA, Kolter R. Flagellar and twitching motility are necessary for Pseudomonas aeruginosa biofilm development. Mol Microbiol. 1998;30(2): 295-304.

51. De Oliveira-Garcia DI, Dall'Agnol M, Rosales M, Azzuz AC, Martinez MB, Girón JA. Characterization of flagella produced by clinical strains of Stenotrophomonas maltophilia. Emerg Infect Dis. 2002;8(9):918-23.

52. Abbady AQ, Al-Daoude A, Al-Mariri A, Zarkawi M, Muyldermans S. Chaperonin GroEL a Brucella immunodominant antigen identified using Nanobody and MALDI-TOF-MS technologies. Vet Immunol Immunopathol. 2012;146(3-4):254-63.

53. Bao Y, Zhai Z, Wang S, Ma J, Zhang W, Lu C. Chaperonin GroEL: a novel phylogenetically conserved protein with strong immunoreactivity of Avian Pathogenic Escherichia coli isolates from duck identified by immunoproteomics. Vaccine. 2013;31(28):2947-53.

54. Ensgraber M, Loos M. A 66-kilodalton heat shock protein of Salmonella typhimurium is responsible for binding of the bacterium to intestinal mucus. Infect Immun. 1992;60(8):3072-8.

55. Bruyn J, Soetaert K, Buyssens P, Calonne I, Coene JL, Gallet X, et al. Evidence for specific and non-covalent binding of lipids to natural and recombinant Mycobacterium bovis BCG hsp60 proteins, and to the Escherichia coli homologue GroEL. Microbiology. 2000;146(7):1513-23. 
56. Clark GW, Tillier ER. Loss and gain of GroEL in the Mollicutes. Biochem Cell Biol. 2010;88(2):185-94.

57. Zhu H, Lee C, Zhang D, Wu W, Wang L, Fang X, et al. Surface-associated GroEL facilitates the adhesion of Escherichia coli to macrophages through lectin-like oxidized low-density lipoprotein receptor-1. Microbes Infect. 2013; 15(3):172-80.

58. Taguchi HJ. Chaperonin GroEL meets the substrate protein as a "load" of the rings. Biochem. 2005;137(5):543-9.

59. Fenton WA, Kashi Y, Furtak K, Horwich AL. Residues in chaperonin GroEL required for polypeptide binding and release. Nature. 1994;371(6498):614-9.

60. Swenson DL, Bukanov NO, Berg DE, Welch RA. Two pathogenicity islands in uropathogenic Escherichia coli J96: cosmid cloning and sample sequencing. Infect Immun. 1996;64(9):3736-43.

61. Hernandes RT, Silva RM, Carneiro SM, Salvador FA, Fernandes MC, Padovan AC, et al. The localized adherence pattern of an atypical enteropathogenic Escherichia coli is mediated by intimin omicron and unexpectedly promotes HeLa cell invasion. Cell Microbiol. 2008;10(2):415-25.

62. Vieira MA, Gomes TA, Ferreira AJ, Knöbl T, Servin AL, Liévin-Le MV. Two atypical enteropathogenic Escherichia coli strains induce the production of secreted and membrane-bound mucins to benefit their own growth at the apical surface of human mucin-secreting intestinal HT29-MTX cells. Infect Immun. 2010;78(3):927-38

\section{Submit your next manuscript to BioMed Central} and we will help you at every step:

- We accept pre-submission inquiries

- Our selector tool helps you to find the most relevant journal

- We provide round the clock customer support

- Convenient online submission

- Thorough peer review

- Inclusion in PubMed and all major indexing services

- Maximum visibility for your research

Submit your manuscript at www.biomedcentral.com/submit 